\title{
Consultorias em Sustentabilidade: polarizações e representatividades de um mercado crescente
}

\section{Sustainability Consulting: polarizations and representativeness of a growing market}

\author{
Elisa Nogueira Novaes Botta ${ }^{1}$ \\ Julio Cesar Donadone ${ }^{1}$
}

\begin{abstract}
Resumo: O presente estudo pretende contribuir com o entendimento do surgimento e crescimento do mercado de Consultorias em Sustentabilidade no Brasil, bem como suas formas de organização. Ilustradas por um banco de dados e entrevistas, são apresentadas as principais características destas empresas brasileiras, bem como as formas de relacionamento com as consultorias internacionais. Ao final, apresenta-se uma cartografia dos polos de influência desse marcado, indicando algumas representatividades.
\end{abstract}

Palavras-chave: Consultoria. Sustentabilidade empresarial. Polaridade. Espaço social.

\begin{abstract}
This study aims to understand the emergence and growth of the Sustainability Consulting market in Brazil as well as its forms of organization. We present the main characteristics of these Brazilian companies, illustrated by a database and interviews, and the forms of relationship with international Consulting. Finally, we present a mapping of the poles of influence related to this marked, indicating some representativeness.
\end{abstract}

Keywords: Consulting. Corporate sustainability. Polarity. Social space.

\section{Introdução}

O recente crescimento da complexidade nos negócios, a globalização, a internacionalização da economia, a integração dos mercados e principalmente, as mudanças e novos formatos organizacionais levantaram inéditas discussões sobre temas relacionados a questões ambientais, sociais e étnicas.

Tais mudanças trouxeram consequências irreversíveis ao ambiente corporativo, que passou a ser entendido como parte responsável pela garantia de preservação do meio ambiente e qualidade de vida das comunidades e de seus funcionários (NOVAES BOTTA, 2013). Segundo Freeman (1989), as empresas devem desenvolver ações em prol não somente dos acionistas, mas de todos os públicos interessados, os stakeholders. Logo, passam a ser responsáveis pelas consequências de suas operações, que envolvem tanto os impactos diretos quanto as externalidades que afetam terceiros. Dessa forma, a função da empresa não mais se limita à maximização dos lucros, há uma exigência pela incorporação de objetivos sociais e ambientais aos planos dos negócios.

Esse novo entendimento sobre a função social da empresa passou a ser traduzido em políticas de Responsabilidade Social e Ambiental desde o final do século XX. No entanto, ao longo de mais de vinte anos, desde seu surgimento, tais temas foram discutidos de forma demasiada em diversos ambientes (acadêmicos, corporativos, governamentais) de formas distintas e independentes (NOVAES BOTTA, 2013).

A criação do conceito de "Desenvolvimento Sustentável" foi um marco, não apenas em termos de cooperação internacional à promoção do ensino, conscientização e treinamento, mas, principalmente, porque chamou atenção, pela primeira vez, para a necessidade de se integrar questões sociais e ambientais.

Tal conceito deu origem à ideia de "Sustentabilidade Empresarial", criada pelo ativista e consultor britâncio John Elkington, no início da década de 1990. Com o objetivo de tornar mais aplicável o Desenvolvimento Sustentável no ambiente corporativo, Elkington (1998) ampliou o conceito, criando os princípios utilizados até hoje, baseados na ideia de People, Planet and Profit [Pessoas, Planeta e Lucro - 3P], ou triple botton line, por meio da qual uma empresa é avaliada pelas suas dimensões sociais, econômicas e ambientais. Tal ideia evidencia, de forma inédita, o cotejamento entre a dimensão ambiental e social no ambiente corporativo.

Esse novo conceito virou uma ideia-força bastante difundida e incorporada por um número

\footnotetext{
${ }^{1}$ Departamento de Engenharia de Produção - DEP, Universidade Federal de São Carlos - UFSCar, Rod. Washington Luís, Km 235, CEP 13565-905, São Carlos, SP, Brasil, e-mail: elisanovaes@gmail.com; donadojc@uol.com.br
} 
significativo de atores. Do radicalismo da organização não governamental Deep Ecology à diretoria de grandes empresas, todos, em uníssono, são a favor da "Sustentabilidade Empresarial" como modelo a ser seguido.

Paralelamente a estas transformações, a dinâmica do campo das empresas de consultoria no Brasil também passava por processo de mudanças durante o mesmo período: o modismo dos gurus gerenciais, atrelado ao processo de downsizing desencadeado no mesmo período, criou um fértil terreno para que a frase "um homem, uma ideia, uma consultoria" fosse observada frequentemente naquele momento. Como consequência, a partir de 1990, observamos o surgimento de tipos específicos e inéditos de consultorias no Brasil, dentre elas, as voltadas exclusivamente a auxiliar na gestão social e ambiental das empresas.

O universo das consultorias, antes dominado pelas Accounting Firms, passa por um processo de heterogeneização naquele momento e, como consequência, novos atores/consultores entram no "jogo", bem como novos serviços passam a ser ofertados. Argumentar-se-á que o universo das Consultorias em Sustentabilidade no Brasil não é um mundo homogêneo, sendo perpassado por algumas divisões relevantes, que resultam em polarizações. É sob esse aspecto que enfocamos o objetivo deste artigo.

Para explorar melhor o tema, este artigo foi organizado em 6 tópicos, além desta introdução. No Tópico 1, é apresentado o objetivo deste estudo. No Tópico 2, é exibida a abordagem da pesquisa: é exposto como será realizado o processo de investigação e, também, são identificados os métodos e tipos de pesquisa utilizados. No Tópico 3, é introduzido o tema da Sustentabilidade Empresarial e indicado o processo de legitimidade que o conceito adquiriu. No Tópico 4, são delineados os grupos de consultorias que oferecem serviços voltados à Sustentabilidade no Brasil. No Tópico 5, são apresentadas as Considerações Finais deste trabalho e, no Tópico 6, as Referências Bibliográficas.

\section{Objetivos do trabalho}

Este estudo tem como objetivo compreender possíveis polaridades desse novo mercado brasileiro, consequentes de diferentes formas de compreensão e comercialização da "Sustentabilidade Empresarial" pelas consultorias no Brasil, num período compreendido entre 1990, quando essas primeiras empresas surgiram, até o ano de 2011. Para tanto, o estudo pretende contribuir com o entendimento do processo de crescimento deste mercado no Brasil, bem como suas formas de atuação, procurando identificar suas características, especificidades do setor no Brasil $\mathrm{e}$ as formas de relacionamento.

\section{Abordagem da pesquisa}

Trataremos o objeto da pesquisa - Consultorias em Sustentabilidade - como um "espaço social", o que significa examinar sua estrutura específica, isto é, como os indivíduos diferem no interior desse mundo a partir de desigualdades entre suas características.

Ao optar pela análise deste mercado e das trajetórias de alguns de seus indivíduos, o interesse desta pesquisa não está restrito nem a uma história factual das instituições, nem tampouco a histórias de vidas individualizadas. Buscamos, sobretudo, compreender a interação entre o universo e as trajetórias de seus atores, na construção de uma possível identidade distintiva de um grupo específico de consultoria e de um espaço social em que os percursos profissionais analisados se inscrevem (RICOUER, 1997).

A Sociologia Econômica torna-se a perspectiva de análise escolhida, na medida em que propõe aplicar estruturas de referência, variáveis e modelos explicativos da Sociologia a um complexo de atividades relacionadas à produção, distribuição, troca e consumo de bens e serviços (SWEDBERG, 2004).

Desta maneira, o presente artigo propõe a observação e análise da recente criação do mercado de Consultorias em Sustentabilidade no Brasil a partir das relações de poder vivenciadas e construídas pelos agentes inseridos nesse espaço social.

\subsection{Metodologia}

Partiremos da análise de um banco de dados criado pela autora durante sua pesquisa de doutoramento, concluída em 2013, com a finalidade de fornecer as primeiras características destas empresas, bem como indicar possíveis polaridades. A abordagem básica de coleta das informações que comporiam o banco de dados foi a análise dos websites dessas empresas e conversas informais com indivíduos envolvidos com o objeto, em situações de Congressos e Seminários.

Num segundo momento, foram realizadas dez entrevistas em profundidade, com o apoio de um roteiro estruturado e com perguntas abertas que maximizam a descrição e a descoberta. Nessa etapa, foram escolhidas dez empresas de consultoria brasileiras, com portes e número de consultores variados. Todos os entrevistados eram consultores, alguns deles os próprios fundadores da empresa.

Para levantar informações sobre as empresas estudadas e, principalmente, compreender a história de vida do coletivo que compõe esse espaço social (os consultores) utilizamos o método da "Prosopografia", que, segundo Stone (1971, p. 46), "[...] é a investigação das características subjacentes comuns a um grupo de atores na história mediante o estudo coletivo de suas vidas." Esse método visa à dimensão comparativa que interessa tanto pelas semelhanças, quanto pelas diferenças (BULST, 2005). 
Essa proposta de investigação, cujas referências clássicas são os trabalhos de Pierre Bourdieu e da Sociologia Econômica, procede estudando um setor econômico na sociedade e também a maneira como este influencia o resto da sociedade ou os fenômenos economicamente condicionados (SWEDBERG, 2004).

A forma de abordagem do problema nesta pesquisa será por método qualitativo. Quanto à forma de explorar os dados, esta pesquisa será descritiva. Sendo um estudo qualitativo, a análise dos dados primou pelos conteúdos e categorização, buscando relacionamentos significativos entre as categorias que corroboraram com os resultados, apresentados ao final. Sobre a amostra estudada, trata-se de uma amostra não probabilística e intencional e de seleção racional (RICHARDSON et al., 1999).

\section{Introdução ao tema}

A "Sustentabilidade Empresarial" criada por John Elkington (1998) e expressa nas ideias de Triple Bottom Line passou a ser difundida mundialmente e, com ela, a ideia de que, caso não fossem mudados os hábitos da população e das empresas, enfrentaríamos sérios problemas em longo prazo. Esse foi um momento crucial para a virada cognitiva da qual este estudo busca dar conta, já que foi a partir dessa crença que se cria a possibilidade de "vender" a Sustentabilidade.

Sob esse aspecto, tornam-se significativas as discussões feitas pela antropóloga Mary Douglas (1982), desenvolvidas como "teoria cultural dos riscos". Segundo essa perspectiva, seria inadequada a separação entre riscos físicos objetivamente calculáveis e percepções individuais subjetivamente influenciadas, pois entre a ciência física e as percepções existiria a cultura em que crenças e valores seriam compartilhados. Desta forma, as percepções de riscos seriam determinadas pela organização social e pela cultura, pois estas forneceriam ao indivíduo os filtros que estruturam suas percepções de risco (DOUGLAS; WILDAVSKY, 1982; PERETTI-WATEL, 2000; MENASCHE, 2003).

A escolha dos riscos com os quais se preocupar depende das formas sociais selecionadas. A escolha dos riscos e a escolha de como viver são realizadas juntas. Cada forma de vida social tem seu próprio elenco de riscos típicos. (DOUGLAS; WILDAVSKY, 1982, p. 8).

Segundo Douglas e Wildavsky (1982), não seria possível alguém se preocupar com todos os riscos potenciais ao mesmo tempo, principalmente quando é crescente a discordância sobre o que é arriscado, como é arriscado e o que deve ser feito a respeito. Sendo assim, as escolhas responderiam a fatores sociais e culturais, não a fatores naturais. Seriam, portanto, parte de um processo sociocultural, em que a evidência científica não necessariamente tem um papel esclarecedor na seleção dos riscos relevantes. Para os autores, as pessoas selecionam determinados riscos como relevantes - guerra, poluição, câncer ou desemprego -, segundo o papel que estes possam ter no reforço da solidariedade social das instituições das quais elas participam. Assim, segundo os autores, valores comuns levam a medos comuns, conduzindo a um acordo implícito sobre o que não temer (DOUGLAS; WILDAVSKY, 1982; GUIVANT, 1998; MENASCHE, 2003).

Ao se considerar que os riscos são percebidos e administrados de acordo com princípios inerentes que reforçam formas particulares de organização social, deixa de ser possível tratar os riscos de forma neutra, com ferramentas metodológicas quantitativas. (GUIVANT, 1998, p. 6).

A partir desta óptica - da análise cultural como elemento para a compreensão das percepções de risco de diferentes sociedades e diferentes grupos - podemos iniciar a compreensão acerca da ascensão e consequente importância da Sustentabilidade Empresarial no ambiente empresarial.

\subsection{Sustentabilidade empresarial no mercado financeiro}

A fim de garantir maior segurança aos investidores nas tomadas de decisões, surgem, a partir do final da década de 1990, os primeiros indicadores com o objetivo de medir o desempenho das empresas. A base para todos é a crença de que as empresas com melhores práticas sociais e ambientais tendem a desempenhar melhor performance financeira comparadas às empresas que estão listadas nos índices considerados tradicionais (ou seja, que reúnem as empresas em uma carteira considerando somente aspectos financeiros) (SARTORE, 2010).

Seguindo tal tendência, algumas Bolsas de Valores têm lançado, recentemente, indicadores financeiros em função do crescimento dos investimentos direcionados às empresas "Sustentáveis". No plano internacional, podemos citar o surgimento do Dow Jones Sustainability Index (DJSI), em 1999, com o objetivo de medir o desempenho financeiro das empresas sustentáveis e o surgimento do Environmental Sustainability Index (ESI) em 2002, com o intuito de comparar os avanços ambientais das nações para as próximas décadas.

No Brasil, em dezembro de 2005, a Bolsa de Valores de São Paulo (BM\&FBOVESPA) lançou o primeiro indicador de rentabilidade das empresas sustentáveis listadas, o Índice de Sustentabilidade Empresarial - ISE. Tal indicador tem:

Objetivo [de] refletir o retorno de uma carteira composta por ações de empresas com reconhecido comprometimento com a responsabilidade social 
e a sustentabilidade empresarial, e também atuar como promotor das boas práticas no meio empresarial brasileiro. [O ISE] mede o retorno médio de uma carteira teórica composta por ações de empresas listadas na BM\&FBOVESPA que se destacam pelo alinhamento estratégico com a sustentabilidade e adoção de práticas que contribuem para o desenvolvimento sustentável. A metodologia aplicada permite avaliar comparativamente o desempenho das empresas sob os diferentes aspectos da sustentabilidade corporativa, baseada em eficiência econômica, equilíbrio ambiental, justiça social e governança corporativa. Constitui um benchmark para o Investimento Socialmente Responsável no Brasil. (BM\&FBOVESPA, 2011).

Em outras palavras, o ISE reúne um grupo de empresas consideradas exemplares em suas práticas desenvolvidas em prol da sociedade, do meio ambiente e da economia (Nota-se que as palavras "sociedade", "meio ambiente" e "economia" se referem ao conceito de Triple Bottom Line - TBL utilizado como referência para o desenvolvimento dos critérios a serem aplicados para o desenvolvimento do Índice de Sustentabilidade Empresarial), e visa oferecer aos investidores uma opção de carteira composta por ações de empresas que apresentam reconhecido comprometimento com a sustentabilidade empresarial.

Para seu desenvolvimento, um Conselho do Índice de Sustentabilidade Empresarial (CISE) foi constituído. Este conselho, composto por representantes de "mundos" distintos - representantes de empresas privadas, da Governança Corporativa, Responsabilidades Social, Responsabilidade Ambiental e Governo -, buscava avançar em direção a um objetivo comum: adquirir legitimidade para classificar e ranquear as empresas que entram e que saem do indicador (Este conselho é formado pelas: Associação Brasileira das Entidades Fechadas de Previdência Complementar - ABRAPP, Associação Nacional nos Bancos de Investimentos - ANBID, Associação dos Analistas e Profissionais de Investimento do Mercado de Capitais - APIMEC, Bolsa de Valores do Estado de São Paulo - BOVESPA, Instituto Brasileiro de Governança Corporativa - IBGC, Instituto Ethos de Responsabilidade Social, Ministério do Meio Ambiente - MMA e Programa das Nações Unidas para o Meio Ambiente - PNUMA).

Em Novembro de 2012, BM\&FBOVESPA anunciou a oitava carteira do Índice de Sustentabilidade Empresarial (ISE), para vigorar de 7 de janeiro de 2013 a 3 de janeiro de 2014. Essa reúne 51 ações de 37 companhias - que representam 16 setores e somam $\mathrm{R} \$ 1,07$ trilhão em valor de mercado, o equivalente a $44,81 \%$ do total do valor das companhias com ações negociadas na BM\&FBOVESPA, valor calculado em 26 de novembro de 2012. Foram convidadas para participar da nova carteira as 183 companhias que detinham as 200 ações mais líquidas da Bolsa em dezembro de 2011 (MARTINS, 2012).

Acompanhando a crença de que investir em empresas sustentáveis é mais rentável no longo prazo, o ISE acaba legitimando a Sustentabilidade no mercado financeiro. Esses incentivos acabaram criando uma considerável demanda por serviços especializados e, como consequência, surgia um fértil terreno para as empresas de consultoria.

\section{O surgimento de um mercado: as Consultorias em Sustentabilidade}

Uma forte estratégia dos consultores para mostrar seu valor e sua capacidade para criar demanda por seus serviços é a disseminação de noções mais amplas de gestão do modismo (KIPPING; KIRKPATRICK, 2011). Os modismos de maior sucesso são aqueles que criam "uma percepção de maior controle" e prometem "grandes avanços no desempenho" (KIESER, 2002, p. 174).

Os consultores, em especial, incluindo os consultores acadêmicos, como Porter, Kaplan e Norton, são vistos por muitos autores (ABRAHAMSON, 1996; FINCHAM; EVANS, 1999; DONADONE, 2001; FAUST, 2002; DAVID; STRANG, 2006) como inventores da maioria das novidades em relação às práticas corporativas. Suas estratégias, construídas a partir da perspectiva "how a non-codified body of knowledge like 'consultancy' could became so apparently influential", enfatizam as incertezas dos gerentes. Tornam-se criadores e disseminadores de um material cultural-cognitivo que "perturba e tranquiliza gerentes" (STURDY, 1997).

No entanto, como um conhecimento não codificado, como o de consultoria, pode se tornar tão influente? Para responder tal questão, os autores indicam a natureza simbólica dos consultores e das consultorias como um "sistema de persuasão poderoso" (FINCHAM, 1999). Temas universais e amplos podem ser vistos pelos consultores como um grande filão de mercado.

A ampliação de serviços voltados à "Gestão Sustentável" pode ser entendida como um desses temas/modismos, e explicado pelo fato de não existir definição ou práticas internacionalmente aceitas sobre o que é ser "Sustentável".

O conceito de Sustentabilidade foi se modificando em virtude da existência de uma disputa entre diversos grupos pela sua definição válida na sociedade. Para que se entenda essa plasticidade, utiliza-se como conceito central a ideia de "polissemia", segundo a extensão sociológica do conceito originário da linguística, proposta por Bourdieu (1989). Nesta acepção, entende-se por polissemia o sentido parcialmente compartilhado para um determinado conceito, sob 
o qual os entendimentos implícitos em torno de sua definição se fixam. Este compartilhamento apenas parcial garante um mínimo de acordo e evita uma crise na relação entre os contendores, para depois evoluir como conflitos simbólicos, em que cada parte tenta registrar como correta a sua versão específica.

Ainda de acordo com a sugestão de Bourdieu (1989), podemos notar que, no começo da década de 1990, a ação simultânea de diversos agentes acaba formando um "campo" em torno do tema, no qual indivíduos originários dos mais diversos subespaços sociais e portadores de elencos de qualidades também das mais diversas áreas acabavam, a despeito da desconfiança e da incompreensão mútuas, colaborando para sua difusão, consolidação e benefícios.

Nesse processo aparentemente natural, acabou-se construindo o entendimento comum mínimo sobre o tema "Sustentabilidade", baseado no triple bottom line. Diversos agentes apropriavam-se da novidade "fashion" em suas respectivas arenas mais ou menos isoladas (consultores, gurus, administradores acadêmicos, editores de livros de administração, organizadores de seminários e administradores), e a adesão ao debate lhes ajudava a alcançar objetivos específicos.

Depois de algum tempo, esse acordo explícito inicial, que colocou o tema na agenda de discussões legítimas no mundo empresarial e na sociedade como um todo, evoluiu para uma luta simbólica, em que os diversos grupos sociais tentaram legitimar sua versão de "Sustentabilidade", desqualificando as demais formas. Cada grupo de atores envolvido com o tema buscava uma compreensão própria sobre o que significava "ser sustentável", ou "quais caminhos seguir para atingir a Sustentabilidade Empresarial", e "quais as práticas que legitimam o conceito", utilizando-as na tentativa de alavancar e fortalecer sua posição frente aos concorrentes do campo.

A partir dessa trama, as novidades organizacionais associadas à "Sustentabilidade" difundiram-se no transcorrer dos anos 2000. Porém, elas somente entraram no cotidiano das empresas após um processo de apropriação e recontextualização pelas primeiras empresas de consultoria que passaram a oferecer serviços voltados à disposição da Sustentabilidade como práticas empresariais que trariam sucesso a longo prazo. Foi nesse momento que o "espírito" foi progressivamente assimilado a práticas já conhecidas no nosso ambiente, fornecendo-lhes um sentido compreensível no sistema social das organizações brasileiras.

No que tange ao universo das consultorias, a disputa pela legitimidade do conceito e pela maneira de colocá-lo em prática evidencia uma disputa entre dois grupos localizados em polaridades opostas. A próxima parte deste trabalho apresentará as características dessas polaridades.

\subsection{As consultorias internacionais}

A fim de apresentar de maneira clara as principais distinções encontradas entre as empresas que oferecem consultorias voltadas à Sustentabilidade no Brasil, optou-se por dividi-las em grupos. Nesta parte, apresentaremos o grupo composto pelas maiores empresas de consultorias internacionais, especializadas em estratégias, que passaram a incluir tais serviços aos pacotes oferecidos. Anteriormente, este era composto pelas empresas Pricewaterhouse Coopers - PwC (2012), Deloitte Touche Tohmatsu Limited - DTTL (2011), KPMG (2013), Ernst \& Young - E\&Y (2012) e Arthur Andersen (2012). Entretanto, em 2001, esta última encerrou suas atividades no mediático escândalo da Enron, no qual foi acusada de complacência com as fraudes realizadas nessa empresa, sendo inocentada pela Suprema Corte dos Estados Unidos da América em 2005, e o grupo, antes conhecido como as Big Five, passou a ser composto por quatro empresas - Big Four - que representam faturamentos mundiais da ordem de US\$ 20 bilhões a US\$ 30 bilhões ao ano cada (BITTENCOURT, 2011).

O Brasil tem sido um dos locais de maior alavanca de retorno para essas empresas. Segundo o Jornal Valor Econômico (RECEITA..., 2011), a receita da E\&Y cresceu aproximadamente $26 \%$ no País, ante expansão de $7 \%$ no mundo. $\mathrm{Na} \mathrm{PwC}$, as receitas avançaram $20 \%$ ou o dobro do resultado global. Movimento semelhante ocorreu na Deloitte, que apurou expansão de faturamento de $15 \%$ no País. A KPMG, que completa o grupo, divulga seus números só no fim do ano - no entanto, no ano de 2010, a empresa faturou mais de 490 milhões de reais só no Brasil (Em março de 2011, a KPMG adquiriu as operações da BDO no Brasil, ganhando mais força no mercado. A estrutura da BDO no Brasil, era composta por 28 sócios, 1.200 funcionários e 18 escritórios. A partir do dia $1^{\circ}$ de abril de 2011 , a BDO Auditores Independentes deixou de existir, dando lugar a BDO RCS Auditores Independentes. Dessa forma, ao se tratar do universo das consultorias internacionais, esta parte da tese irá trabalhar com o grupo das Big Four, mais a BDO). Ainda segundo o Jornal Valor Econômico (RECEITA..., 2011), essas empresas se beneficiam no país - na área de auditoria e de consultoria - da formalização das empresas de middle market - em que querem tomar recursos para crescer, seja em bancos, em emissões externas, ou em oferta pública inicial - Initial Public Offering - IPOs.

Buscando acompanhar a demanda de seus clientes, essas consultorias internacionais vêm inovando os serviços oferecidos, incluindo a novidade voltada à "Gestão Sustentável".

A consultoria [BDO] realizou uma pesquisa para identificar o universo de empresas que realizam ações de sustentabilidade [...] Hoje há mais de 
mil empresas que publicam relatórios sociais. Detectamos 4 mil empresas que fazem ações relacionadas à sustentabilidade, que vão da escolha socialmente responsável de fornecedores a ações de governança corporativa, entre outras. (BDO, 2010).

Esses novos serviços vêm acompanhados de discursos que reforçam a ideia positiva da Sustentabilidade Empresarial, apontando uma tendência de aceitação para a inserção do tema no Brasil. Além disso, baseiam-se no modelo criado por John Elkington (1998), do triple bottom line como suporte ao conceito de "Sustentabilidade" que oferecem - carregam em seus discursos a tendência internacional baseada na ideia de que empresas que investem em Sustentabilidade e agem de acordo com as normas de Responsabilidade Socioambiental tendem a ficar menos suscetíveis a processos trabalhistas e ambientais e, portanto, estão menos suscetíveis à restrições à capacidade de a empresa continuar operando.

Essa abordagem do risco, no entanto, está muito mais direcionada às empresas que buscam entrar ou manter-se nas Bolsas de Valores. Segundo o consultor e especialista em Sustentabilidade Gustavo Pimentel, em entrevista cedida ao Jornal Valor Econômico (VIALLI, 2014), quando uma empresa enfrenta alguma crise, o analista e o investidor refazem as projeções de receita e, consequentemente, do preço do papel. Se existe a iminência de algum problema afetar a geração de caixa da companhia, é preciso embutir esse risco na cotação. Segundo ele, o objetivo da análise sob o viés da Sustentabilidade é avaliar de forma mais precisa este risco. O consultor pondera que este trabalho segue a mesma linha do processo tradicional da análise fundamentalista. A diferença é que são adicionados critérios sociais e ambientais à avaliação econômico-financeira da companhia.

Quando o investidor aborda como a empresa atua nessa direção, está avaliando não apenas se a companhia leva o meio ambiente em consideração nas decisões dos seus negócios, mas acima de tudo, se ela possui uma boa gestão de riscos. $\mathrm{O}$ viés da sustentabilidade é considerado uma excelente análise de riscos, pois aprofunda e toca em temas que não são percebidos pelas avaliações tradicionais, antecipando temas e prevenindo a empresa de eventos indesejáveis. (MEIBAK, 2012).

Dessa forma, a ideia da Sustentabilidade, proposta pelas empresas internacionais de consultoria segue o apelo do "risco". No entanto, essa é uma crença instituída que ainda não foi empiricamente provada, segundo Sartore (2010). O mercado financeiro, bem como as consultorias internacionais, trabalha com tal perspectiva a partir de índices e indicadores, criados na tentativa de "mensurar o imensurável":

Seja a partir da mente de um analista técnico, seja pela de um analista fundamental, a busca pelo domínio do acaso, ou ainda, pela sua previsão inseriu-se no espaço financeiro. A crença nas regularidades no mercado financeiro dotou àqueles que poderiam identificá-las de poderes semelhantes aos do Estado Estatístico. Ambos baseiam-se em classificações, índices e taxas para tomar as suas decisões, tornam o “improvável” ou o "pouco provável” em algo mensurável, fabricam indicadores pelos quais a sociedade (a qual inclui o mercado financeiro) vai ser classificada e construída. (SARTORE, 2010, p. 107)

A ideia de que a diminuição dos riscos apresenta um maior retorno financeiro a longo prazo passou a ser forte aliada da disseminação do discurso da Sustentabilidade e sua importância para os investidores por estas empresas.

Sendo assim, existe um padrão de serviços oferecidos por este grupo de consultorias, bem como um padrão de empresas contratantes (clientes). O serviço de Duo Dilligence, por exemplo, dentro do pacote de "Sustentabilidade", é o mais frequentemente oferecido por estas empresas de consultorias.

Outro serviço observado nessas empresas está relacionado à assessoria para indicadores como o ISE. Sendo assim, pode-se afirmar que a "Sustentabilidade Empresarial", oferecida por essas consultorias está diretamente voltada ao mercado financeiro. Algumas destas empresas, como Deloitte Touche (2011) e KPMG (2013), são claras quanto à finalidade do serviço. No website da primeira, é apresentado o serviço

Execução de diagnósticos baseados nos seguintes padrões nacionais e internacionais - Índice de Sustentabilidade Empresarial - ISE.

$\mathrm{Na}$ segunda empresa:

Suporte na consolidação das informações e preenchimento de questionários de referência propostos pelo ISE - Índice de Sustentabilidade Empresarial, DJSI - Dow Jones Sustainability Index, CDP - Carbon Disclosure Project, entre outros.

Outra característica que vem dar suporte à atuação deste grupo de consultorias é a forte ligação com serviços internacionais. Observamos tal fato quando nos deparamos com alguns nomes de serviços oferecidos, em inglês, como "Definição de metas e indicadores de performance socioambiental (Key Performance Indicators - KPIs)"; "Avaliação do impacto e quantidade de recursos hídricos consumidos 
por produto (water footprint)"; "Assessoria para cumprimento de normas de sustentabilidade (BonSucro, RTRS - RoundTable on Responsible Soybean, SojaPlus", etc.

Todos esses serviços oferecidos traduzem a especificidade dessas empresas, bem como o know how em lidar com temas internacionais. Tal fato torna-se um diferenciador entre os grupos tratados por esta tese: as consultorias internacionais apresentam como principal legitimidade as "experiências internacionais" e, por esse motivo, não necessitam provar as competências de seus consultores. Esse é outro aspecto recorrente entre as Big Four. Ao apresentar em seus websites os profissionais/consultores que compõem a equipe prestadora de tais serviços, são pouco detalhistas. O website da Ernst \& Young Terco (2012) descreve:

A equipe de Sustentabilidade e Mudanças Climáticas atua de forma sinérgica com todos os demais setores da Ernst \& Young Terco [...] Uma equipe integrada e multidisciplinar, formada a partir de um quadro de profissionais especialistas no assunto, ajuda sua empresa a identificar as pessoas certas para convidar para discussões e a desenvolver recomendações personalizadas, inovadoras e eficazes.

Outro serviço frequentemente oferecido dentro do pacote de "Sustentabilidade", vendido por estas empresas, está relacionado à elaboração, desenvolvimento ou verificação de Relatórios. Donadone (2001) aponta que a elaboração de relatórios foi um dos serviços responsáveis pela formação e desenvolvimento do setor:

[...] a formação e desenvolvimento do setor de consultorias em muito foi fundamentado nos relatórios sobre a saúde financeira das empresas, como nos emblemáticos Surveys Bank [Elaboração de análises de saúde financeira das empresas] (DONADONE, 2001, p. 112).

A consultoria KPMG (2013), por exemplo, oferece o serviço "Climate Change and Sustainability Services" (CC\&S), que engloba, dentre outros; Diagnóstico de riscos, Preenchimento de questionários de referência propostos pelo ISE; Verificação independente de Relatórios de Sustentabilidade; e Balanços Sociais. Segundo o website da empresa,

O foco da prática de CC\&S é auxiliar as organizações, dos mais variados portes e setores, a entender o contexto de sustentabilidade onde se situam e a identificar a melhor estratégia de atuação e de reporte dos dados de sustentabilidade. Parte desse processo diz respeito à identificação dos riscos - políticos, regulatórios, de mercado, entre outros - e das oportunidades advindas deste novo cenário. (KPMG, 2013).
A consultoria Ernst \& Young Terco (2012) apresenta seu serviço com o nome "Mudança Climática e Sustentabilidade", a empresa Deloitte Touche Tohmatsu (2011) oferece o serviço "Consultoria ambiental e sustentabilidade", que compreende temas ambientais e sociais: Mudanças Climáticas; Princípios do Equador; Terceiro Setor; Duo Diligence; Sistemas integrados de gestão ambiental, saúde e segurança do trabalho, responsabilidade social, segurança alimentar e qualidade; Responsabilidade Social Corporativa e Avaliação dos impactos ambientais nas demonstrações financeiras.

Ao analisar os serviços oferecidos por essas empresas, percebemos que a BDO é a única empresa do grupo das internacionais que trabalha com o conceito da Sustentabilidade restrito apenas à elaboração de Balanços Sociais. As outras quatro consultorias trabalham com o conceito de Sustentabilidade associando serviços com abrangência Social e Ambiental.

No entanto, a oferta de alguns desses serviços, como a elaboração de Relatórios de Sustentabilidade, não é exclusividade dessas empresas internacionais. São também oferecidos por outro grupo de consultorias no Brasil, as consultorias que oferecem serviços voltados exclusivamente à Sustentabilidade.

Apesar de características diferentes quanto ao tamanho e à nacionalidade dessas empresas, esse outro grupo parece competir pelo mesmo mercado. Sendo assim, torna-se essencial entendermos "Qual o diferencial das empresas desse segundo grupo?", "Quais fatores as legitimam no espaço social?". A próxima parte buscará responder tais questões.

\subsection{Gestão para a sustentabilidade como exclusividade: as consultorias nacionais}

O segundo grupo é composto por empresas de consultoria nacionais que oferecem serviços voltados apenas à Sustentabilidade. Segundo Novaes Botta (2013), das 73 empresas deste tipo existentes no País até o ano de 2011 , mais de $70 \%$ estão localizadas no Estado de São Paulo e, dessas, 94\% estão situadas na região da Grande São Paulo. Além disso, diferentemente das internacionais, as empresas que fazem parte desse grupo são empresas de pequeno porte, e a grande maioria (aproximadamente 71\%) apresenta um quadro de consultores com no máximo 5 profissionais.

Para se compreender as estratégias de sobrevivência dessas empresas, é preciso identificar os capitais que estão em jogo:

Os pretendentes podem acumular capital de autoridade específico ao levarem a sério os valores e as virtudes exaltados pela representação oficial da atividade legítima [...] Os recém-chegados 
reintroduzem, incessantemente no campo, um ardor e um rigorismo de reformistas. (BOURDIEU, 2001, p. 22).

Ao analisar a forma com que essas empresas se apresentam em seus websites, notamos uma frequência quanto à importância dos títulos acadêmicos de seus consultores. Uma das empresas desse grupo salienta:

A [...]é uma empresa composta por Doutores, Mestres e Profissionais de mercado que há anos atuam no campo da Comunicação Social Estratégica para Grandes Empreendimentos. Através da nossa expertise sobre a Responsabilidade SocioAmbiental, agregamos valor a sua empresa qualificando a Comunicação com os Públicos de interesse. (Com a finalidade de manter em sigilo a identidade das empresas pesquisadas, optou-se por não citá-las ou fazer referências diretas neste trabalho, grifo do autor).

Seguindo a mesma linha, outra empresa de consultoria brasileira apresenta em seu website o "Curriculum" de seu único consultor, valorizando sua trajetória acadêmica: Doutorado, Livros Publicados e Curriculum Lattes.

A apresentação de seus consultores valorizando novos capitais, como o acadêmico, parece ser uma das estratégias que essas novas empresas encontraram para se legitimar no espaço social. Conforme aponta Bourdieu (2002, p. 23), “A luta pela dominação [...] conduz necessariamente os pretendentes a submeter à discussão os esquemas de produção e avaliação ortodoxos, produzidos e impostos pelas instituições dominantes." (BOURDIEU, 2002, p. 23).

Além disso, pudemos constatar que esse grupo também reconhece o conceito da Sustentabilidade baseado no triple bottom line, já que a maioria dos websites faz referência a este modelo.

Apesar de as estratégias de legitimação serem semelhantes entre as empresas deste grupo, no que concerne a serviços oferecidos, pôde-se constatar, a partir da análise do banco de dados, que aproximadamente $65 \%$ dessas empresas apresentam pacotes voltados à apenas um dos pilares que o conceito baseado no triple botton line prevê. Destas, cerca de $40 \%$ oferecem serviços voltados apenas à Responsabilidade Social, e 25\% oferecem apenas serviços voltados à Gestão Ambiental. Ou seja, fugindo do pressuposto, apenas $35 \%$ das empresas que compõem o universo estudado oferecem serviços que cotejam Responsabilidade Social (RS) e Gestão Ambiental (GA), conforme prevê os preceitos da Sustentabilidade Empresarial.

Tal constatação nos possibilitou a criação de um segundo polo de forças, com a finalidade de propor um recorte que pudesse dar conta das divergências relacionadas à interpretação da Sustentabilidade Empresarial, bem como as articulações sociais de seus atores/consultores, que contribuem para tal. O critério utilizado para a inserção destas empresas em um dos polos foi a análise dos serviços oferecidos, descritos em seus websites. Nessa etapa, colocamos em um dos polos as consultorias que ofereciam serviços que de fato cotejassem exclusivamente Responsabilidade Social e Gestão Ambiental e, no outro, as consultorias que, apesar de se apresentarem como "Consultorias em Sustentabilidade", ofereciam serviços voltados à RS ou GA. O primeiro "grupo" passou a ser chamado de "Consultorias em Sustentabilidade Cotejantes" (CSC) e era composto por 26 empresas; e o segundo, "Consultorias em Sustentabilidade Parcial" (CSP), era composto por 47 empresas de consultoria.

No grupo CSC, a maioria das empresas também está localizada nas cidades de São Paulo (56\%) e Rio de Janeiro (20\%). Sobre o número de consultores fixos, quase $70 \%$ das empresas deste grupo possuem no máximo 5. A maioria dos agentes pertence ao sexo masculino (76\%), 76\% atuam nas cidades de São Paulo e Rio de Janeiro, 90\% não possuem passagem pela Fundação Getúlio Vargas (FGV), estágio Profissional no Exterior, Passagem pela Academia, Experiência em Instituições do Governo e Participação na criação do ISE. Além disso, quase metade desses profissionais possui Mestrado (47\%), boa parte deles têm alguma especialidade no tema e $33 \%$, passagem pelo Terceiro Setor (NOVAES BOTTA, 2013).

No grupo das "Consultorias em Sustentabilidade Parcial", aproximadamente $61 \%$ das empresas estão localizadas na cidade de São Paulo, no entanto, diferente da localização das consultorias do grupo anterior, quase $35 \%$ das consultorias desse grupo estão distribuídas entre cidades menores (contra 24\% do grupo anterior), como Americana (SP), Bertioga (SP), Campinas (SP), São Bernardo do Campo (SP), Carapicuíba (SP), Curitiba (PR), Balneário Camburiú (SC), Joinvile (SC), Porto Alegre (RS) e Belo Horizonte (MG). Além disso, enquanto o primeiro grupo apresentava $20 \%$ das empresas localizadas na cidade do Rio de Janeiro, este grupo apresenta apenas $4 \%$.

Com relação aos serviços ofertados por esse grupo, os voltados ao "Social" são mais frequentes que os voltados ao "Ambiental". Sobre os cursos de graduação dos consultores apareceram cerca de 20 cursos diferentes na área de Ciências Humanas, no entanto, o curso que aparece com maior frequência (30\%) é Administração de Empresas. A área de Biológicas apresentou uma variação menor: as formações dos consultores estavam divididas entre 9 cursos, com destaque à graduação em Biologia, que abrange cerca de $43 \%$ dos profissionais desta área. Finalmente, a área de Exatas apresentou uma variação de 14 cursos, sendo o curso de Engenharia Ambiental o mais frequente entre os consultores desta área, com $34 \%$. 
A continuidade na academia para algum tipo de especialização, também não é frequente neste grupo (CSP): menos de 30\% possuem título de Mestre, e os Doutores não chegam a $10 \%$ do universo estudado. E ainda, ao cotejar tais informações, percebemos que $31 \%$ dos consultores não possuem nenhum desses títulos.

Ainda sobre o grupo, cerca de $20 \%$ dos consultores possuem algum tipo de MBA, $26 \%$ têm algum tipo de especialização, e menos de $10 \%$ possuem algum estágio no exterior. A passagem pela FGV também é pouco frequente (pouco mais de 10\%), e nenhum consultor deste grupo teve participação na criação do ISE. Tais fatos explicam o perfil dos serviços oferecidos não estarem voltados ao mercado financeiro.

Além desse novo mercado não apresentar homogeneidade quanto à formação acadêmica e trajetória profissional, conforme indicado, também não possui nenhum tipo de certificação "clara" que legitime o agente como consultor.

A segunda etapa para análise dos grupos foi a realização de dez entrevistas, seis delas direcionadas aos consultores do grupo CSC, e quatro aos CSP. O objetivo dessas entrevistas era confirmar as indicações elaboradas na etapa anterior, além de nos fornecer dados que possibilitassem entender a construção de mundo, as formas de atuação e a representação social dos atores inseridos no espaço social estudado $(\mathrm{O}$ grupo das consultorias internacionais não participou desta etapa devido à dificuldade encontrada pela autora em contatar agentes que representassem as consultorias).

A escolha dos consultores/empresas que fariam parte dessa etapa da pesquisa foi baseada nas recorrências de algumas ideias, serviços e posicionamentos sobre assuntos relacionados à Sustentabilidade Empresarial revisados na primeira fase, além da busca por uma amostra heterogênea de empresas em relação ao número de consultores, localização e ano de surgimento.

A fim de garantir a privacidade das consultorias pesquisadas, nomeamos as seis "entrevistadas" do grupo CSC por "C1", "C2", "C3", "C4", "C5", e "C6". Da mesma maneira, as empresas entrevistadas do grupo CSP foram chamadas de "P1", "P2", "P3" e "P4".

O Quadro 1 sintetiza as informações encontradas.

\section{Considerações finais}

Este artigo identificou que, embora todas as empresas pesquisadas indiquem trabalhar com o conceito da Sustentabilidade a partir do triple botton line, existem polaridades no espaço das consultorias em Sustentabilidade no Brasil.

Primeiramente, identificamos polaridades entre as consultorias internacionais e nacionais no que tange aos serviços oferecidos e forma de abordagem da
Sustentabilidade. Nesta distinção, em um dos polos, estão as Big Four: buscando acompanhar a demanda de seus clientes, essas consultorias vêm inovando os serviços oferecidos, incluindo os voltados à "Gestão Sustentável". Aproveitando a legitimidade que obtiveram ao longo de sua existência, esse grupo carrega em seu discurso a tendência internacional baseada na ideia de que empresas que investem em Sustentabilidade tendem a ficar menos suscetíveis a processos trabalhistas e ambientais, e, portanto, estão menos suscetíveis a restrições à capacidade de a empresa continuar operando. Essa abordagem do risco está muito mais direcionada às empresas que buscam entrar ou manter-se nas Bolsas de Valores. Dessa forma, os serviços oferecidos por essas consultorias são bem específicos, como Duo Dilligence e assessoria para indicadores como o ISE.

Tal fato indica que os clientes que procuram essas consultorias estão envolvidos com a Bolsa de Valores, de alguma forma, e a busca por serviços voltados à Sustentabilidade visa satisfazer exigências deste nicho - acionistas e Bovespa.

No outro polo, encontram-se as empresas de consultoria nacionais. No que tange ao entendimento da Sustentabilidade, todas as empresas também salientam proximidade com o triple botton line. No entanto, ao analisar os serviços descritos em seus websites, identificamos uma segunda polaridade, ou subpolaridade, que fora confirmada com as entrevistas: algumas empresas de fato cotejam fatores sociais e ambientais, conforme prevê o conceito, e passaram a ser chamadas nesta pesquisa de "Consultorias em Sustentabilidade Completa"; e outras apresentam serviços voltados à apenas um desses aspectos, e passaram a ser chamadas de "Consultorias em Sustentabilidade Parcial".

Completadas as entrevistas, pudemos identificar algumas tendências nesta subpolaridade: em relação aos serviços oferecidos, identificamos pouca especificidade. Ao contrário das consultorias internacionais, grande parte dessas nacionais oferece um atendimento mais local e não voltado ao mercado financeiro (salvo poucas exceções). O entendimento sobre o comportamento do consumidor, desde o que pensa sobre Sustentabilidade até a influência que exerce sobre suas decisões de compra, é de grande valia para decisões estratégicas dos clientes que procuram essas consultorias.

As bases de legitimação dessas consultorias nacionais evidenciam a bagagem acadêmica de seus profissionais, como títulos de Mestres e Doutores.

No entanto, de maneira geral, embora seja frequente a referência ao conceito do $3 \mathrm{P}$, muitas dessas empresas não cotejam aspectos sociais e ambientais. Entretanto, seus dirigentes têm consciência de tal disparate, já que os discursos, indicados pelas entrevistas, apontam 


\begin{tabular}{|c|c|c|c|c|c|c|c|c|c|c|c|c|c|c|c|c|}
\hline$\vec{E}$ & 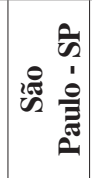 & ్ㅗㅀ & $x$ & $x$ & & & & & & & $\sim$ & 疍 & $\stackrel{\stackrel{R}{Z}}{ }$ & 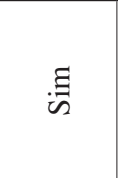 & 胥 & 胥 \\
\hline$\tilde{\theta}$ & 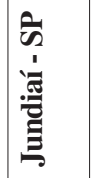 & ్ํำ & & & & & & & $x$ & & $\simeq$ & 茜 & 污 & 胥 & 見 & 胥 \\
\hline$\tilde{I}$ & 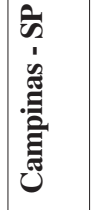 & 气ิ̀े & & & & & & & $x$ & $x$ & $m$ & 部 & 污 & 胥 & 胥 & 胥 \\
\hline $\bar{a}$ & 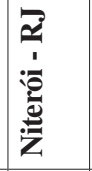 & 气ิેి & $x$ & $x$ & & & $x$ & & & & $\nabla$ & 部 & 㣽 & 喅 & 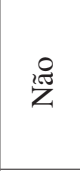 & 囱 \\
\hline ש &  & 을 & & $x$ & & $x$ & & & & $x$ & $\sim$ & $\left|\begin{array}{c}\mathbb{I} \\
z \\
Z\end{array}\right|$ & 污 & 胥 & 胥 & 尽 \\
\hline 8 & 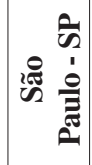 & હેิ & $x$ & & $x$ & $x$ & $x$ & & & & $m$ & 寻 & घี & ह & हี & 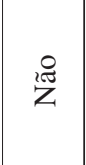 \\
\hline U & 量 & 을 & $x$ & & $x$ & & & & & $x$ & - & 寻 & घี & $\stackrel{\stackrel{I}{Z}}{Z}$ & $\stackrel{i \mathbb{R}}{Z}$ & 疍 \\
\hline 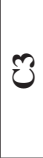 & 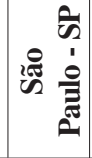 & 气ิેి & & & $x$ & $x$ & & & $x$ & $x$ & $r$ & 放 & 汸 & $\stackrel{\Re}{Z}$ & $\stackrel{\Re}{Z}$ & $\stackrel{\Re}{Z}$ \\
\hline$\tilde{U}$ & 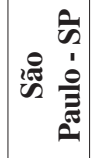 & $\hat{\mathrm{z}}$ & $x$ & $x$ & $x$ & $x$ & $x$ & & $x$ & & ৯े & 跑 & $\stackrel{\Xi}{\sim}$ & 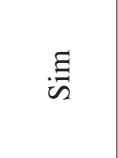 & 敫 & 寻 \\
\hline $\bar{U}$ & 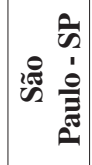 & 今ે & & $x$ & $x$ & & & $x$ & $x$ & & $\nabla$ & 站 & 污 &  & 寻 & 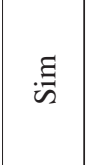 \\
\hline 㺼 & 宽 & 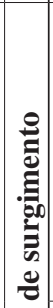 & 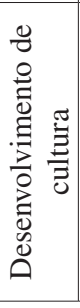 & 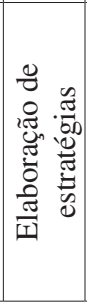 & 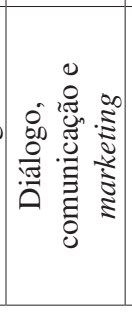 & 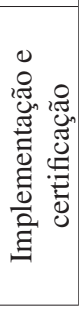 & 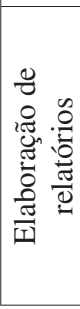 & 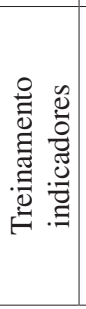 & 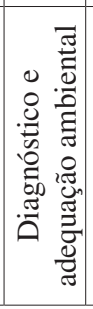 & 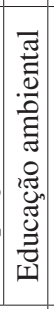 & 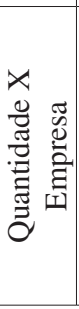 & 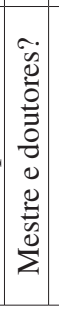 & 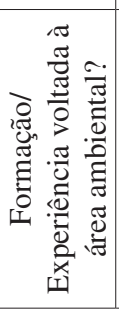 & 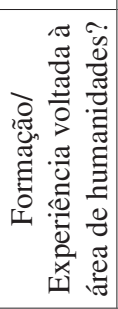 & 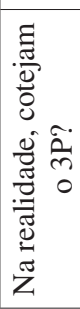 & 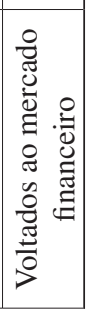 \\
\hline & & 妾 & \multicolumn{8}{|c|}{ 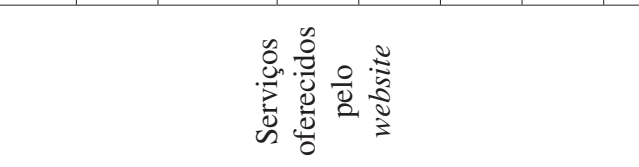 } & \multicolumn{4}{|c|}{ 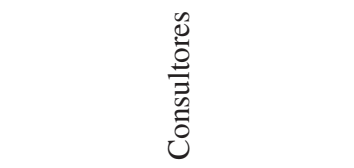 } & \multicolumn{2}{|c|}{ 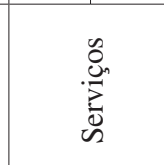 } \\
\hline
\end{tabular}


pleno conhecimento acerca do conceito criado por John Elkington (1998).

Algumas consultorias do grupo das Consultorias em Sustentabilidade Completa apresentam características que as diferenciam no espaço social. No que tange aos serviços oferecidos, se aproximam do grupo das Big Four (C1 e C2). A trajetória de seus fundadores abrange passagem pelo mercado financeiro e terceiro setor, e o perfil de seus consultores indica diversidade de formação, bem como titulações acadêmicas. Tais características apontam para um perfil dominante no que concerne à formação de seus profissionais e serviços oferecidos. Dessa forma, estão aptas a receberem grandes clientes, multinacionais, e ofertarem serviços completos no que concerne à Sustentabilidade Empresarial, que abrangem aspectos sociais, ambientais e voltados ao mercado financeiro.

As consultorias nacionais que não possuem tais características, e que após as entrevistas foi constatado que não são completas no que tange aos serviços oferecidos, mas parciais, ficam em falta quanto ao know how necessário para guiarem seus clientes no caminho da "Sustentabilidade Empresarial" e, portanto, tornam-se o grupo dominado no espaço social em questão.

A adoção do conceito da "Sustentabilidade Empresarial" por estas empresas torna-se uma estratégia para se legitimarem dentro do espaço social, no entanto, evidencia uma disputa entre atores representantes do lado ambiental versus social. $\mathrm{Na}$ medida em que a Sustentabilidade se apresenta como um conceito polissêmico, favorece ofertas de serviços voltados apenas a questões ambientais e sociais.

Sendo assim, as categorias que criam maiores distâncias na análise das empresas apontadas nesta pesquisa, e que, portanto, nos permitem identificar possíveis oposições neste espaço, foram as soluções oferecidas pelas consultorias (locais/internacionais), e o entendimento da Sustentabilidade a partir do conceito baseado no triple botton line (3P).

Pensando numa cartografia dos polos de influência do espaço social de consultoria em Sustentabilidade no Brasil, criamos o Eixo X: proximidade (esquerda)/ distância (direita) de soluções locais e o Eixo Y: proximidade (cima)/distância (baixo) do conceito de Sustentabilidade baseado no 3P, conforme aponta a Figura 1.

A cartografia dos polos de influência desse espaço social demonstrou que o espaço das consultorias em Sustentabilidade no Brasil possui certa representatividade, pois apresenta profissionais com formação em finanças dialogando com profissionais vindos do terceiro setor e da academia. Esta representatividade demonstra que o espaço das consultorias em Sustentabilidade é constituído por uma convergência de interesses ao mesmo tempo que mantém a distinção entre os que atuam na esfera

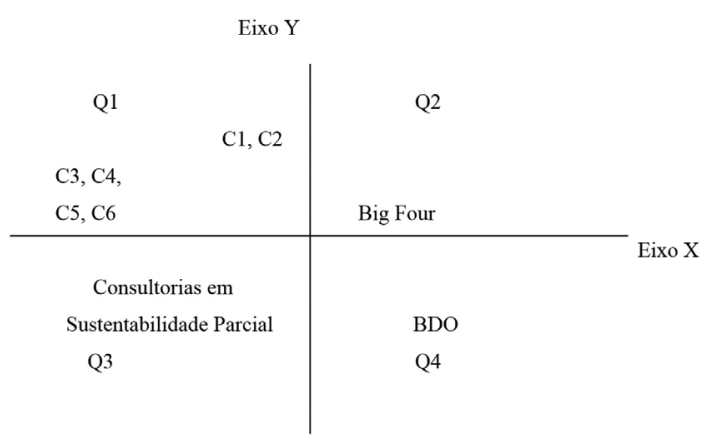

Figura 1. Cartografia dos polos de influência do espaço social de consultoria em Sustentabilidade no Brasil.

das finanças ou voltados ao mercado financeiro (principalmente no que tange ao perfil dos serviços oferecidos), e os que não o fazem.

O eixo y expõe uma oposição entre as empresas nacionais; de pequeno porte; com serviços pouco específicos; com consultores Mestres/Doutores em áreas de Biológicas e Humanas; com pouca experiência com consultoria e com passagem pelo terceiro setor versus as empresas internacionais; de grande porte; com fortes ligações aos serviços internacionais; específicos; voltados a empresas de grande porte e multinacionais.

Assim, de um lado, o polo acadêmico, com foco de atuação em empresas não multinacionais e de outro, o lado não acadêmico, com foco de atuação no setor multinacional e Bolsa de Valores.

Esta oposição demonstra que, no que concerne às consultorias em Sustentabilidade, observa-se um espaço com um polo mainstream versus um polo heterodoxo. O polo mainstream tem como categorias associativas a predominância das empresas com uma conexão internacional, atores com formação focada em negócios, que não passaram pelo terceiro setor e serviços com aproximação com o ISE. O polo heterodoxo compreende as empresas nacionais, com indivíduos que não possuem formação em finanças, ou seja, com formação acadêmica não mainstream [ou seja, não têm formação em economia, administração ou contabilidade] com aproximação com o terceiro setor.

No que tange à oferta de serviços, podemos afirmar que no primeiro quadrante (Q1) estão as "Consultorias em Sustentabilidade Cotejantes" C3, C4, C5 e C6. As empresas C1 e C2 estão entre o Q1 e o Q2, já que, ao ofertarem serviços voltados ao ISE, aproximam-se das internacionais. No Q2, estão as Big Four, com exceção da BDO. No Q3, estão as "Consultorias em Sustentabilidade Parcial” e, no Q4, está a BDO, já que esta é a única consultoria internacional que não coteja os três aspectos previstos pela Sustentabilidade.

Esta heterogeneidade é um dos indícios de que se trata de um processo de construção de uma realidade social nova. O fato de o conceito de "Sustentabilidade" 
ser polissêmico abre diversas possibilidades de interpretação ou de "oferta de serviços". A disputa dentro do espaço social estudado faz com que cada grupo apresente suas "armas", buscando legitimidade e, portanto, mais clientes.

\section{Agradecimentos}

À CAPES - Coordenação de Aperfeiçoamento de Pessoal de Nível Superior, que financiou o presente estudo.

\section{Referências}

ABRAHAMSON, E. Management fashion. Academy of Management Review, v. 21, n. 1, p. 254-285, 1996.

BDO. Disponível em: <http://www.bdobrazil.com.br/pt/ index.php>. Acesso em: 07 out. 2010.

ARTHUR ANDERSEN. St. Charles. Disponível em: <http:// www.arthurandersen.com>. Acesso em: 5 maio 2012.

BITTENCOURT, A. As gigantes de auditoria e o bom momento do Brasil. ValorInveste, 05 out. 2011. Disponível em: <http://www.valor.com.br/valor-investe/ casa-das-caldeiras/1038050/gigantes-de-auditoria-e-obom-momento-do-brasil>. Acesso em: 04 out. 2013.

BM\&FBOVESPA. Disponível em: <www.bmfbovespa. com.br/>. Acesso em: 23 out. 2012.

BM\&FBOVESPA. Índice de Sustentabilidade Empresarial - ISE. 2011. Disponível em: <www. bmfbovespa.com.br/indices/ResumoIndice. aspx? Indice=ISE $>$. Acesso em: 12 ago. 2012.

BOURDIEU, P. Coisas ditas. São Paulo: Brasiliense, 1989.

BOURDIEU, P. Les conditions sociales de la circulation internationale des idées. Actes de la recherche en sciences sociales, v. 145, n. 145, p. 3-8, 2002. http:// dx.doi.org/10.3917/arss.145.0003

BOURDIEU, P. O costureiro e sua grife: contribuição para uma teoria da magia. Educação em Revista, n. 34, p. 7-66, 2001.

BULST, N. Sobre o objeto e o método da prosopografia. Tradução de Cybele Crosseti de Almeida. Politéia: História e Sociedade, v. 5, n. 1, p. 47-67, 2005.

DAVID, R. J.; STRANG, D. When fashion is fleeting: transitory collective beliefs and the dynamics of TQM Consulting. Academy of Management Journal, v. 49, n. 2, p. 215-233, 2006. http://dx.doi.org/10.5465/ AMJ.2006.20786058

DELOITTE TOUCHE TOHMATSU LIMITED - DTTL. Disponível em: <https://www.deloitte.com/br >. Acesso em: 13 nov. 2011.

DONADONE, J. C. Os hunos já chegaram: dinâmica organizacional, difusão de conceitos gerenciais e a atuação das consultorias. 2001. 123 f. Tese (Doutorado em Engenharia)-Escola Politécnica, Universidade de São Paulo - USP, São Paulo, 2001.

DOUGLAS, M. Risk and blame: essays in cultural theory. London: Routledge, 1992. http://dx.doi. org/10.4324/9780203430866

DOUGLAS, M.; WILDAVSKY, A. Risk and culture: an essay on the selection of technological and environmental dangers. Berkeley: University of California Press, 1982.
ELKINGTON, J. Cannibals with forks: the triple bottom line of 21st century business. Canada: NSP, 1998.

ERNST \& YOUNG - E\&Y. Disponível em: <www.ey.com/ BR/pt/Home>.Acesso em: 25 ago. 2012.

FAUST, M. Consultancies as actors in knowledge Arenas: evidence from Germany. In: KIPPING, M.; ENGWALL, L. (Ed.). Management consulting: emergency and dynamics of a knowledge industry. Oxford: Oxford University Press, 2002. p. 146-163.

FINCHAM, R. The consultant-client relationship: critical perspectives on the management of organizational change. Journal of Management Studies, v. 36, n. 3, p. 335-351, 1999. http://dx.doi.org/10.1111/1467-6486.00139

FINCHAM, R.; EVANS, M. The consultants' offensive: reengineering: from fad to technique. New Technology, Work and Employment, v. 14, n. 1, p. 32-44, 1999. http://dx.doi.org/10.1111/1468-005X.00051

FREEMAN, C. New technology and catching up. The European Journal of Development Research, v. 1, n. 1, p. 85-89, 1989. http://dx.doi. org/10.1080/09578818908426503

GUIVANT, J. S. A trajetórias das análises de risco: da periferia ao centro da teoria social. Revista Brasileira de Informações Bibliográficas em Ciências Sociais, n. 46, p. 3-38, 1998.

KIESER, A. Managers as marionettes? Using fashion theories to explain the success of consultancies. In: KIPPIN, M.; ENGWALL, L. (Ed.). Management consulting. Oxford: Oxford University Press, 2002. p. 167-183.

KIPPING, M.; KIRKPATRICK, I. O desenvolvimento da consultoria de gestão empresarial entre a estrutura e a agência. In: DONADONE, J. C.; JARDIM, M. A. C. (Org.). As centralidades e fronteiras das empresas do século 21. Bauru: Edusc, 2011. p. 249-285.

KPMG. Disponível em: <http://www.kpmg.com/br/pt/ paginas/default.aspx>. Acesso em: 25 out. 2013.

MARTINS, T. Bovespa anuncia nova carteira do ISE para 2013. Envolverde, 29 nov. 2012. Disponível em: <http:// envolverde.com.br/economia/bovespa-anuncia-novacarteira-do-ise-para-2013/>. Acessado em: 28 jan. 2014.

MEIBAK, D. CVM defende gestão de risco para viabilizar crescimento sustentável. Valor Econômico, 29 nov. 2012. Disponível em: <http://www.valor.com.br/ empresas/2917174/cvm-defende-gestao-de-risco-paraviabilizar-crescimento-sustentavel/>. Acesso em: 06 jun. 2013.

MENASCHE, R. Os grãos da discórdia e o risco à mesa: um estudo antropológico das representações sociais sobre os cultivos e alimentos transgênicos no Rio Grande do Sul. 2003. 279 f. Tese (Doutorado em Antropologia Social)-Universidade Federal do Rio Grande do Sul - UFRGS, Porto Alegre, 2003.

NOVAES BOTTA, E. N. Passos em falso? Os processos de formação do espaço das consultorias em sustentabilidade no Brasil. 2013. 198 f. Tese (Doutorado em Engenharia de Produção)-Universidade Federal de São Carlos - UFSCar, São Carlos, 2013.

PERETTI-WATEL, P. Sociologie du risque. Paris: Armand Colin, 2000.

PRICEWATERHOUSE COOPERS - PwC. Disponível em: <http://www.pwc.com.br/>. Acesso em: 06 maio 2012. 
RECEITA da Ernst \& Young avança 7,6\% no mundo. Valor Econômico, 05 out. 2011. Disponível em: $<$ http://www.valor.com.br/impresso/eu-investimentos/ receita-da-ernst-young-avanca-76-no-mundo $>$. Acessado em: 20 dez. 2012.

RICHARDSON, R. J. et al. Pesquisa social: métodos e técnicas. 3. ed. São Paulo: Atlas, 1999.

RICOUER, P. Tempo e narrativa. São Paulo: Papirus, 1997. v. 3.

SARTORE, M. S. Convergência de elites: a sustentabilidade no mercado financeiro. 2010. 207 f. Tese (Doutorado em Ciências Sociais)-Universidade Federal de São Carlos - UFSCar, São Carlos, 2010.
STONE, L. La prosopographie. Daedalus, v. 100, n. 1, p. 46-79, 1971.

STURDY, A. The consultancy process: an insecure business? Journal of Management Studies, v. 34, n. 3, p. 389-413, 1997. http://dx.doi.org/10.1111/1467-6486.00056

SWEDBERG, R. Sociologia econômica: hoje e ontem. Tempo Social, v. 16, n. 2, p. 7-34, 2004. http://dx.doi. org/10.1590/S0103-20702004000200001

VIALLI, A. É hora de soluções. Jornal Valor Econômico, São Paulo, 28 ago. 2014. Disponivel em: <http:// www.valor.com.br/empresas/3670558/e-hora-desolucoes\#ixzz3BgbgBuLo>. 